\title{
RETINOBLASTOMA AND ITS CLINICOPATHOLOGICAL CORRELATION AT A TERTIARY CARE CENTRE
}

\author{
Shruti Chandrakar'1, Ashok Kumar C²
}

${ }^{1}$ Senior Resident, Department of Pathology, Pt. JNM Medical College, Raipur.

2Professor and HOD, Department of Ophthalmology, Pt. JNM Medical College, Raipur.

ABSTRACT
BACKGROUND
Retinoblastoma is the commonest childhood primary malignant intraocular neoplasm that is often characterised by spontaneous
regression. They display photoreceptor differentiation. This study provides the clinical presentations and histological profiles of
retinoblastoma in a tertiary care centre in Chhattisgarh State, in Central India.

\section{MATERIALS AND METHODS}

A retrospective study of clinically and histologically verified retinoblastoma at Pt JNM Medical College, Raipur, Chhattisgarh from January 2010 to December 2011 was undertaken. The clinical and histological features were analysed using the patient's case folder and surgical pathology records.

\section{RESULTS}

There were 50 patients, 32 males and 18 females (M:F ratio 1.7:1), age range from 51/2 months to 6 years with 42 eyeball tumours histologically confirmed retinoblastoma during the study period. Proptosis with chemosis was the most common clinical presentation (76.1\%). Bilaterality was 15\% in this study. Enucleation and Exenteration combined with chemotherapy were offered to $31(75 \%)$ and $11(25 \%)$ patients respectively.

\section{CONCLUSION}

Moderately differentiated type with extensive areas of tumour necrosis was the commonest histological pattern. 27 (65\%) of the patients died before completing the course of chemotherapy.

\section{KEYWORDS}

Retinoblastoma, Pathology.

HOW TO CITE THIS ARTICLE: Chandrakar S, Kumar AC. Retinoblastoma and its clinicopathological correlation at a tertiary care centre. J. Evolution Med. Dent. Sci. 2017;6(72):5079-5082, DOI: 10.14260/jemds/2017/1104

\section{BACKGROUND}

Retinoblastoma (RB) is a rare embryonic tumour, but commonest primary malignant intraocular tumour of childhood. ${ }^{[1,2]}$ In the United States of America, retinoblastoma occurred in 1 of every 15000 live births,[3] whereas in developing countries of Africa and Asia reports showed that it occurred in 1:18000 live births. $[4,5,6]$ Retinoblastoma accounted for more than $50 \%$ of all ocular and orbital malignancies of all age groups in African series.[5,6,7,8] However, in Caucasians, it is the second most common tumour following malignant melanoma.[3,9] The most common and obvious sign of retinoblastoma is an abnormal appearance of the retina as viewed through the pupil, the medical term for which is leukocoria, also known as amaurotic cat's eye reflex.[1] Other signs and symptoms include deterioration of vision, a red and irritated eye with glaucoma, and faltering growth or delayed development. Some children with retinoblastoma can develop a squint, ${ }^{[4]}$ commonly referred to as "cross-eyed" or "wall-eyed" (strabismus). Retinoblastoma presents with advanced disease in developing countries and eye enlargement is a common finding.

Financial or Other, Competing Interest: None.

Submission 27-07-2017, Peer Review 24-08-2017,

Acceptance 30-08-2017, Published 07-09-2017.

Corresponding Author:

Dr. Shruti Chandrakar,

\#34/A/1, Maulshree Vihar, VIP Road,

Raipur-492006.

E-mail: shrutichandrakar9388@gmail.com

DOI: $10.14260 /$ jemds $/ 2017 / 1104$
Depending on the position of the tumours, they may be visible during a simple eye exam using an ophthalmoscope to look through the pupil. A positive diagnosis is usually made only with an examination under anaesthetic (EUA). A white eye reflection is not always a positive indication of retinoblastoma and can be caused by light being reflected badly or by other conditions such as Coats' disease.

The presence of the photographic fault red eye in only one eye and not in the other may be a sign of retinoblastoma. A clearer sign is "white eye" or "cat's eye".

Retinoblastoma occurs in sporadic (60\%) - usually unilateral or germline [hereditary] (40\%) forms; the later manifesting either as unilateral or bilateral disease and characterised by early onset and predisposition to developing secondary non-ocular, intracranial malignancies termed Trilateral Retinoblastoma.[10,11] The RB gene is located in the long arm of chromosome 13 (13q14) and the gene is believed to be a recessive suppressor; thus, it requires the loss, deletion, mutation or inactivation of both copies of the gene at the 13q14 locus for RB to develop which correlates with the two "hits" theorised by Knudson.[12,13,14] Retinoblastoma is a cancer of the retina. When a baby is growing in the womb, the eyes are one of the first things to develop. In the very early stages the eyes have cells called retinoblasts that grow very fast. Later, they stop growing and develop into mature retinal cells that can detect light.

Very rarely, the immature retinoblasts continue to grow very fast and do not turn into mature retinal cells. Instead, they grow out of control and develop into a cancerous tumour called retinoblastoma. 
If the tumour is not treated, the cells continue to grow and the cancer fills most of the eyeball. It can also spread to other parts of the eye and begin to block the flow of fluid inside the eye. This leads to a build-up of pressure and can cause loss of vision.

Fortunately, most retinoblastomas are found early and successfully treated before they spread outside the eyeball. If they do spread, they can go to anywhere in the body including the brain, bones and lymph nodes. They can be difficult to treat once they have spread.

Prenatal and postnatal prediction of susceptibility to inherited RB using recombinant DNA markers is now possible.[15] Somatic amplification of the MYCN oncogene is responsible for some cases of non-hereditary, early-onset, aggressive, unilateral retinoblastoma. Although MYCN amplification accounted for only $1.4 \%$ of retinoblastoma cases, researchers identified it in $18 \%$ of infants diagnosed at less than 6 months of age. Median age at diagnosis for MYCN retinoblastoma was 4.5 months, compared with 24 months for those who had non-familial unilateral disease with two RB1 gene mutations. This would make genetic counselling for familial (Hereditary) RB more accurate, leading to an earlier tumour detection and effective therapy. The clinical presentation of RB includes leucocoria, strabismus, conjunctival chemosis, proptosis, and even blindness, which are attributed to late presentation and diagnosis.[2,16] In spite of the treatment modalities such as enucleation, radiotherapy, photocoagulation, chemotherapy and even exenteration as in extraocular involvement, the mortality from RB in our environment is very high. $[2,5,6,16,17,18]$

\section{Endophytic Growth}

Endophytic growth occurs when the tumour breaks through the internal limiting membrane and has an ophthalmic appearance of a white-to-cream mass showing either no surface vessels or small irregular tumour vessels. This growth pattern is typically associated with vitreous seeding, wherein small fragments of tissue become separated from the main tumour. In some instances, vitreous seeding may be extensive and allow tumour cells to be visible as spheroid masses floating in the vitreous and anterior chamber, simulating endophthalmitis or iridocyclitis, and obscuring the primary mass. Secondary deposits or seeding of tumour cells into other areas of the retina may be confused with multicentric tumours.

\section{Exophytic Growth}

Exophytic growth occurs in the subretinal space. This growth pattern is often associated with subretinal fluid accumulation and retinal detachment. The tumour cells may infiltrate through the Bruch's membrane into the choroid and then invade either blood vessels or ciliary nerves or vessels. Retinal vessels are noted to increase in calibre and tortuosity as they overlie the mass.

\section{Diffuse Infiltrating Growth}

This is a rare subtype comprising $1.5 \%$ of all retinoblastomas. It is characterised by a relatively flat infiltration of the retina by tumour cells but without a discrete tumour mass. The obvious white mass seen in typical retinoblastoma rarely occurs. It grows slowly compared with typical retinoblastoma.

\section{MATERIALS AND METHODS}

A total of 42 ocular surgical specimens from 50 patients with clinical diagnosis of retinoblastoma at the Ophthalmology Department of Pt. JNM Medical College, Raipur, Chhattisgarh from January 2010 to December 2011 and registered at the pathology department for histological verification were retrospectively studied. The age, sex, presenting symptoms, duration of symptoms, site, management and other adjunct treatment were obtained from the patient's case notes and analysed. Paraffin sections stained by standard haematoxylin and eosin (H \& E) were retrieved and reviewed by one of the Authors. Special stains, Methyl green-pyronin (MGP) for calcium deposition and pearl blue reaction for haemosiderin pigments were employed where necessary. Each optic nerve was examined for involvement in tumour spread up to the line of transection. . The histological diagnosis was based on cell morphology, degree of differentiation, presence of Flexner-Wintersteiner rosettes, optic nerve infiltration by tumour cells to the cut end of the optic nerve and tumour necrosis. Clinical photographs of some of the patients as well as photomicrographs were also included for illustration.

\section{RESULTS}

42 cases of retinoblastoma were diagnosed from 50 patients during the 2-year interval which accounted for $33.3 \%$ of the total number of ocular and orbital tumour cases seen at the eye clinic and $10.5 \%$ of childhood malignancies during the same period at Pt JNM Medical College. There were 32 males and 18 females, giving a male to female ratio of $1.7: 1$. The ages of the children ranged from $5 \frac{1}{2} 2$ months to 6 years with a mean age of 29 months (SD 0.78). The commonest clinical presentation in our experience was proptosis with associated conjunctival chemosis (76.1\%). This was followed by leucocoria $61.9 \%$, and hypopyon $42.8 \%$. Eyelid swelling and blindness were observed in approx. $30 \%$ of the cases each Table 1.

\begin{tabular}{|c|c|c|}
\hline Signs and Symptoms & No. of Cases & Percentage \\
\hline $\begin{array}{c}\text { Proptosis and conjunctival } \\
\text { chemosis }\end{array}$ & 32 & 76.1 \\
\hline Leucocoria & 26 & 61.9 \\
\hline Hypopyon & 18 & 42.8 \\
\hline Eyelid swelling & 13 & 30.9 \\
\hline Blindness & 12 & 28.5 \\
\hline Eye discharge & 6 & 14.2 \\
\hline Pain & 4 & 9 \\
\hline Globe perforation & 4 & 9 \\
\hline Table 1. Clinical Signs and Symptoms \\
\hline
\end{tabular}

\begin{tabular}{|c|c|c|}
\hline Histological Features & No. of Cases & Percentage \\
\hline Poorly differentiated & 15 & 35.7 \\
\hline Moderately differentiated & 22 & 52.3 \\
\hline Well differentiated & 5 & 11.9 \\
\hline Table 2. Characteristic Histological Features of \\
Retinoblastoma Differentiation \\
\hline
\end{tabular}

\begin{tabular}{|c|c|c|}
\hline Flexner-Wintersteiner & 13 & 30.9 \\
\hline Pseudorosette & 29 & 69.0 \\
\hline \multicolumn{2}{|c|}{ Rosette } \\
\hline
\end{tabular}




\begin{tabular}{|c|c|c|}
\hline Optic nerve & 16 & 38 \\
\hline Skeletal muscle & 1 & 2.3 \\
\hline Lacrimal gland & 2 & 4.7 \\
\hline Vascular emboli & 2 & 4.7 \\
\hline \multicolumn{2}{|c|}{ Microscopic Spread } \\
\hline
\end{tabular}

\begin{tabular}{|c|c|c|}
\hline Necrosis & 34 & 80.9 \\
\hline Dystrophic calcification & 11 & 26.1 \\
\hline Haemorrhage & 10 & 23.8 \\
\hline Siderosis & 4 & 9.5 \\
\hline Cholesterol slits & 3 & 7.1 \\
\hline Basophilia & 3 & 7.1 \\
\hline \multicolumn{2}{|c|}{ Others }
\end{tabular}

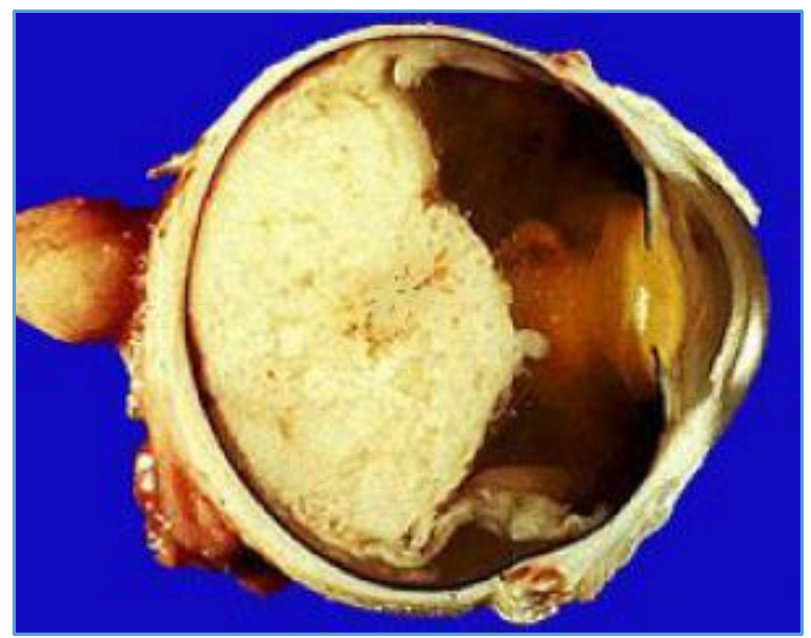

Gross

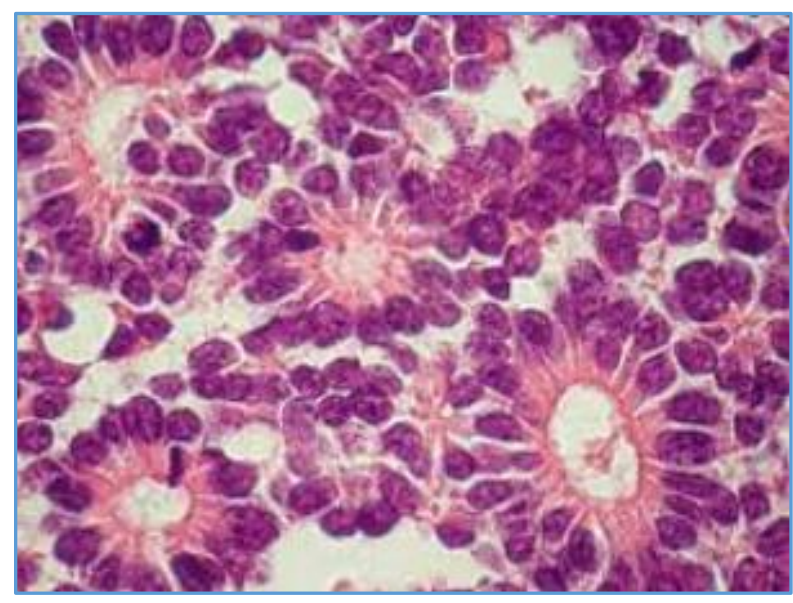

Flexner-Wintersteiner

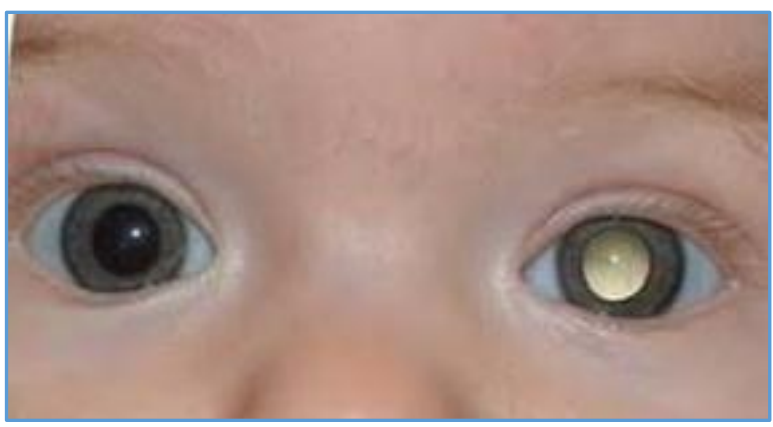

Retinoblastoma
In this study, Retinoblastoma accounted for $33 \%$ of all cases of ocular and orbital malignancies in our centre that compares well with the findings in other studies where the incidence varies from $34-55$ percent.[6,19,20] Similarly, our present experience of Retinoblastoma accounting for $10.5 \%$ of all childhood cancer and the commonest childhood intraocular tumour corroborates findings in African series $^{[19,20,21,22]}$ but high when compared with developed countries where $2.4-4 \%$ has been reported.[2,23] We reported a male to female sex ratio of 1.7:1. This differs with the observation of no sex predilection in other studies.[14,17,23,24] Our patients appeared to present very late as the average age of the children at the time of diagnosis was 29 months. This is comparable to similar findings in the developing countries, $[6,8,17,19]$ it is high when compared with the reports of western countries.[14,23,24,25] The late presentation in our study could be due to among other causes like lack of awareness of the disease, delayed referral prompted by consultation with traditional medical practitioners and poor affordability and accessibility to available medical facilities.

No single case of RB was reported in an adult in this series which agrees with the findings of Olurin et al.[19] Proptosis with conjunctival chemosis was the commonest clinical presentation manifesting in $76.1 \%$ of our patients. This is at variance with findings in other studies where leucocoria and strabismus were observed.[16,17,23] This picture is attributed to delay in presentation of the patients for diagnosis and treatment. This opinion is supported by the claim that proptosis is the result of orbital involvement.[16] Also Erwenne et al concluded in their study of 158 consecutive cases of RB that extraocular disease was strongly dependent on the age at diagnosis and lateness of referral.[25] The incidence of bilateral RB in this series is 15\% that agrees with the findings in some African series.[17,19] In Zambia it is $4 \%$ whereas in the western countries such as Germany, England and Wales, the incidence is higher.[22,23] The disparity may be associated with incomplete data or due to higher incidence of unilateral (sporadic) RB over bilateral cases in India. Histologically, the two characteristic arrangements of cells that are pathognomonic of RB are Flexner-Wintersteiner rosette and fleurette representing an attempt to differentiate into photoreceptor cells. Well-differentiated tumours are characterised by the presence of Flexner-Wintersteiner rosettes. In this communication, 22 eyes (52.3\%) were of moderately differentiated type; compared with other studies the above findings are comparable.[17,23]

\section{CONCLUSION}

Retinoblastoma is the commonest malignant intraocular tumour of childhood, mostly of moderately differentiated type histologically and characterised by high mortality in our centre. There is need for improved accessibility to health facilities and the importance of genetic counselling should be emphasised.

\section{ACKNOWLEDGEMENT}

I would like to acknowledge the departments of Ophthalmology and Pathology for allowing me to conduct my study. 


\section{REFERENCES}

[1] Ashley DJB. Retinoblastoma. In: Evans histological appearances of tumour. $3^{\text {rd }}$ edn. Edinburgh, Churchill Livingstone 1978:462-4.

[2] Shields JA, Augsburger JJ. Current approaches to the diagnosis and management of retinoblastoma. Survey of Ophthalmology 1981;25(6):347-72.

[3] Tamboli A, Podgor MJ, Horm JW. The incidence of retinoblastoma in the United States: 1974 through 1985. Archives of Ophthalmology 1990;108:128-32.

[4] Klauss V. Retinoblastoma in developing countries. Community Eye Health 1990;3(5):1-2.

[5] Abiose A, Adido J, Agarwal SC. Childhood malignancies of the eye and orbit in northern Nigeria. Cancer 1985;55(12):2889-93.

[6] Ajaiyeoba IA, Pindiga HU, Akang EE. Tumours of the eye and orbit in Ibadan. East African Medical Journal 1992;69:487-9.

[7] Vingtain P, Negrel AD, Ginoux J, et al. Orbital and ocular tumours in the republic of Mali. Med Trop (Mars) 1986;46(2):147-53.

[8] Dawodu OA, Hannah BF. Enucleation and evisceration in the Gambia. Nigerian Journal of Ophthalmology 2000;8(1):29-33.

[9] Swanson MW, Cloud G. A retrospective analysis of primary eye cancer at the University of Alabama at Birmingham 1958-1988. Part 2: eyelid tumours. Journal of American Optom Association 1991;62(11):820-3.

[10] Abramson DH. Second nonocular cancers in retinoblastoma: a unified hypothesis. The Franceschetti lecture. Ophthalmic Genetics 1999;20(3):193-204.

[11] Kivela T. Trilateral retinoblastoma: a meta-analysis of hereditary retinoblastoma associated with primary ectopic intracranial retinoblastoma. Journal of Clinical Oncology 1999;17(6):1829-37.

[12] Paulino AC. Trilateral retinoblastoma: is the location of the intracranial tumour important? Cancer 1999;86(1):135-41.
[13] De Potter PV, Shields CL, Shields JA. Clinical variation of trilateral retinoblastoma: a report of 13 cases. Journal of Pediatrics Ophthalmology Strabismus 1994;31(1):26-31.

[14] Knudson AG. The genetics of childhood cancer. Cancer 1975;35(3 suppl):1022-6.

[15] Cavenee WK, Murphree AL, Shull MM, et al. Prediction of familial predisposition to retinoblastoma. New England Journal of Medicine 1986;314:1201-7.

[16] Kanski JJ. Retinoblastoma. In: Clinical ophthalmology a systematic approach. $4^{\text {th }}$ edn. Oxford, ButterworthHeinemann 1999:337-42.

[17] Akang EE, Ajaiyeoba IA, Campbell OB, et al. Retinoblastomas in Ibadan, Nigeria: IIclinicopathologic features. West African Journal of Medicine 2000;19:6-11.

[18] Ezepue UF, Maduka-Okafor C. Retinoblastoma: a review of occurrence, available treatment and prognosis at Enugu, Nigeria. Nigerian Journal of Ophthalmology 1995;3:1-5.

[19] Olurin 0, Williams A0. Orbito-ocular tumours in Nigeria. Cancer 1972;30(2):580-7.

[20] Tijani SO, Elesha SO, Banjo AA. Morphological patterns of paediatric solid cancers in Lagos, Nigeria. West African Journal Medicine 1995;14:174-80.

[21] Welbeck J, Hesse A. Pattern of childhood malignancy in Korle-Bu Teaching Hospital, Ghana. West African Journal Medicine 1998;17(2):81-4.

[22] Childhood cancer. In: Cancer in Africa: Epidemiology and prevention. Parkin DM, Ferlay J, Cherif HM, et al. (eds). Lyon. IARC Scientific Publication 2003;153:38196.

[23] Sang DN, Albert DM. Retinoblastoma: clinical and histopathologic features. Human Pathology 1982;13(2):133-47.

[24] Jensen RD, Miller RW. Retinoblastoma epidemiologic characteristics. New England Journal of Medicine 1971;285(6):307-11.

[25] Erwenne CM, Franco EL. Age and lateness of referral as determinants of extra-ocular retinoblastoma. Ophthalmic-paediatric Genetics 1989;10(3):179-84. 